\title{
Penilaian Perkembangan Bayi Risiko Tinggi dan Rendah pada Usia 3 dan 6 Bulan dengan Instrumen Bayley Scales of Infant and Toddler Development Edisi III
}

\author{
Rini Purwanti, Imral Chair, Soedjatmiko \\ Departemen Kesehatan Anak Fakultas Kedokteran Universitas Indonesia/Rumah Sakit Cipto \\ Mangunkusumo
}

\begin{abstract}
Latar belakang. Enam bulan pertama kehidupan merupakan kesempatan emas untuk melakukan deteksi dini gangguan tumbuh kembang. Bayi risiko tinggi (risti) merupakan kelompok yang rentan terhadap keterlambatan perkembangan. Contoh instrumen penilaian perkembangan yang terbaru adalah Bayley scales of infant and toddler development Edisi III (Bayley III).

Tujuan. Mengetahui gambaran keterlambatan perkembangan bayi risiko tinggi dan rendah pada usia 3 dan 6 bulan.

Metode. Penelitian kohort prospektif dilakukan terhadap bayi risti yang mendapat perawatan di Unit Neonatologi Rumah Sakit Cipto Mangunkusumo (RSCM) dan bayi risiko rendah di empat Posyandu serta Poliklinik Tumbuh Kembang RSCM selama periode Mei - Desember 2010. Penilaian perkembangan dilakukan dengan instrumen Bayley III pada usia koreksi 3 dan 6 bulan.

Hasil. Proporsi laki-laki lebih banyak pada kedua kelompok. Proporsi gagal tumbuh pada kelompok risti lebih banyak dan meningkat pada usia 6 bulan $(20,6 \%$ vs 3,6\%). Median nilai komposit pada area area kognitif dan motorik lebih rendah untuk bayi risti $(\mathrm{p}<0,05)$. Risiko relatif gangguan perkembangan untuk area kognitif, komunikasi, motorik dan adaptif pada usia 6 bulan adalah 3,1 (IK95\% 1,29-7,91), 3,5 (IK95\% 1,4-11,7), 4,1 (IK95\% 1,5-11,5), dan 4 (IK95\% 1,23-135). Jumlah morbiditas berpengaruh terhadap kejadian keterlambatan di seluruh area pada usia 6 bulan $(\mathrm{p}<0,05)$.

Kesimpulan. Perkembangan bayi risti di area kognitif dan motorik pada usia 3 dan 6 bulan terlambat. Risiko keterlambatan perkembangan lebih jelas terlihat pada usia yang lebih tua. Banyaknya morbiditas perinatal mempengaruhi derajat keterlambatan. Sari Pediatri 2012;14(1):24-9.
\end{abstract}

Kata kunci: bayi risiko tinggi, keterlambatan perkembangan, Bayley III

Alamat korespondensi:

Dr. Rini Purwanti, Sp.A, RS Jatisampurna Jl. Studio ANTV, Jatiraden. Jatisampurna, Bekasi. Telp. (021) 8451457, E-mail: rinipurwanti_dr@ yahoo.com

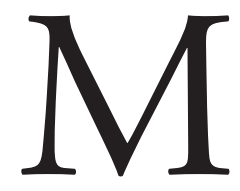

asa enam bulan pertama kehidupan merupakan kesempatan emas untuk melakukan deteksi awal, serta penilaian tumbuh kembang dan intervensi 
dini pada seorang anak. Dasar tersebut mendasari konsep intervensi sedini mungkin sebelum usia 6 bulan. ${ }^{1}$ Deteksi dini gangguan perkembangan dapat dilakukan sejak usia 2 minggu, namun beberapa studi menyatakan bahwa keterlambatan perkembangan di usia 3 bulan lebih memiliki arti klinis untuk memprediksi luaran di usia berikutnya. ${ }^{2,3}$ Bayi risiko tinggi adalah kelompok bayi yang memiliki kemungkinan lebih besar untuk mengalami kematian dan kesakitan termasuk gangguan tumbuh kembang. ${ }^{4,5}$ Penyebab risiko tinggi pada bayi adalah gangguan pada masa prenatal, saat kelahiran, dan pascanatal. ${ }^{6}$ Prevalens keterlambatan perkembangan pada bayi dengan masalah perinatal di Indonesia antara $17,1 \%-26 \%{ }^{7,8}$ Secara umum angka kejadian keterlambatan perkembangan pada populasi nasional adalah $12,8 \%-28,5 \%$. ${ }^{9.10}$

Penilaian keterlambatan perkembangan anak memerlukan instrumen yang sudah divalidasi, memiliki sensitivitas dan spesifisitas tinggi, mudah digunakan, sederhana, dan singkat dan selalu direvisi. ${ }^{11}$ Sebuah instrumen evaluasi perkembangan yang memiliki syarat-syarat tersebut adalah Bayley scales of infant and toddler development (Bayley III). ${ }^{12,13}$ Tujuan penelitian untuk mengetahui gambaran keterlambatan perkembangan pada bayi risiko tinggi dan bayi risiko rendah pada usia 3 dan 6 bulan, dengan tujuan khusus mengetahui risiko keterlambatan pada semua area perkembangan.

\section{Metode}

Studi kohort prospektif telah dilakukan selama periode Mei - Desember 2010 di Poliklinik Tumbuh Kembang Departemen Ilmu Kesehatan Anak Rumah Sakit Cipto Mangunkusumo (RSCM) dan Posyandu Kecamatan Cikini RT 2,3,4 RW 2 Jakarta Pusat, Posyandu Kampung Melayu RW 3 Jakarta Timur. Subjek penelitian diambil secara konsekutif pada bayi risiko tinggi yang mendapatkan perawatan di Unit Neonatologi RSCM selama Februari - Juli 2010 dan bayi risiko rendah yang datang untuk kunjungan bayi sehat di Posyandu/Poliklinik Tumbuh Kembang yang lahir selama periode yang sama. Kriteria inklusi untuk bayi risti adalah memiliki salah satu atau lebih morbiditas perinatal dan pernah mendapatkan perawatan selama periode perinatal. Kriteria inklusi untuk bayi risiko rendah adalah tidak memiliki morbiditas perinatal dan tidak pernah mendapatkan perawatan selama periode perinatal. Kriteria eksklusi untuk kedua kelompok apabila tidak memiliki kelainan kongenital yang berdampak pada gangguan perkembangan. Dilakukan persetujuan orangtua dan persetujuan dari Komite Etik, Fakultas Kedokteran Universitas Indonesia. Pemeriksaan dilakukan pada usia 3 dan 6 bulan dengan menggunakan instrumen Bayley III. Analisis statistik menggunakan program SPSS 17.

\section{Hasil}

Studi dilakukan selama periode Mei - Desember 2010. Pada awal penelitian didapat 125 bayi, terdiri atas 65 bayi risti dan 60 bayi risiko rendah. Pada akhir penelitian jumlah subjek 118 bayi, terdiri atas 63 kelompok risti dan 55 kelompok risiko rendah diikuti sampai akhir pengamatan. Karakteristik subjek digambarkan pada Tabel 1. Rasio laki-laki dibanding perempuan 1,3:1 untuk bayi risti dan 1,9:1 untuk bayi risiko rendah. Morbiditas perinatal utama pada kelompok risti adalah prematuritas $(38,1 \%)$, asfiksia $(33,3 \%)$ dan sepsis $(28,6 \%)$.

Didasarkan 85\% usia ibu antara 20-35 tahun untuk kedua populasi. Orangtua memiliki tingkat pendidikan menengah 74,6\% untuk kelompok risti dan $56,4 \%$ untuk risiko rendah. Pendapatan keluarga mayoritas berasal dari golongan sedang $(\mathrm{Rp} 1,5-<$ 2,5 juta/bulan), 42,9\% untuk kelompok risti dan $34,5 \%$ untuk risiko rendah. Status sosial ekonomi keluarga berpengaruh pada morbiditas perinatal $(\mathrm{p}<0,05)$.

Rerata berat badan kelompok risti adalah 4951,6 gram $(\mathrm{SB} \pm 841,8)$ dan 6525,4 gram $(\mathrm{SB} \pm 654,6)$ pada usia 3 dan 6 bulan, sedang pada kelompok risiko rendah 5682,7 gram $(\mathrm{SB} \pm 1008,7)$ dan 7200 gram $(\mathrm{SB} \pm 759,1)$. Rerata tinggi badan untuk kelompok risti pada usia 3 dan 6 bulan adalah $56,8 \mathrm{~cm}(\mathrm{SB} \pm 3,1)$, dan $59 \mathrm{~cm}(\mathrm{SB} \pm, 5)$, sedangkan pada kelompok risiko rendah adalah $63 \mathrm{~cm}(\mathrm{SB} \pm 2,9)$ dan $64,7 \mathrm{~cm}(\mathrm{SB} \pm 3.2)$. Kejadian gagal tumbuh meningkat pada usia 6 bulan untuk kelompok risti.

Perkembangan dinilai dengan menggunakan nilai komposit dari instrumen Bayley III. Median nilai komposit untuk area kognitif dan motorik lebih rendah pada kelompok risti pada dua kali pemeriksaan, tetapi tidak terdapat perbedaan 
Rini Purwanti dkk: Penilaian perkembangan bayi risiko tinggi dan rendah pada usia 3 dan 6 bulan dengan instrumen Bayley III

Tabel 1. Karakteristik subjek

\begin{tabular}{lcc}
\hline Variabel & $\begin{array}{c}\text { Risiko tinggi } \\
(\mathrm{n}=63)\end{array}$ & $\begin{array}{c}\text { Risiko rendah } \\
(\mathrm{n}=55)\end{array}$ \\
\hline $\begin{array}{l}\text { Jenis kelamin (\%) } \\
\quad \text { Laki-laki }\end{array}$ & $36(57,1)$ & $36(65,6)$ \\
Usia gestasi (\%) minggu & $45(38,1)$ & - \\
$\quad<37$ & $17(14,4)$ & $55(100)$ \\
$\quad 37-41$ & $1(0,8)$ & \\
$\quad>41$ & $56(88,9)$ & $55(100)$ \\
Status gizi pada kelahiran n (\%) & $7(11,1)$ & \\
$\quad$ SMK & & $43(78,2)$ \\
$\quad$ KMK & $30(47,6)$ & $1(1,8)$ \\
Cara kelahiran n (\%) & $4(6,3)$ & $11(20.0)$ \\
$\quad$ Per vaginam & $29(46)$ & 3000 \\
$\quad$ Per vaginam dengan alat & 1800 & 49,65 \\
$\quad$ Per abdominal & 43 & \\
Median berat badan, gram & & \\
Panjang lahir, cm & & \\
& &
\end{tabular}

Tabel 2. Sebaran median nilai komposit

\begin{tabular}{|c|c|c|c|c|c|c|}
\hline \multirow{2}{*}{ Area } & \multicolumn{2}{|c|}{ Usia 3 bulan } & \multirow[b]{2}{*}{$\mathrm{p}$} & \multicolumn{2}{|c|}{ Usia 6 bulan } & \multirow[b]{2}{*}{$\mathrm{p}$} \\
\hline & Risti & Risiko rendah & & Risti & Risiko rendah & \\
\hline Kognitif & 90 & 100 & 0,001 & 95 & 105 & 0,001 \\
\hline Komunikasi & 94 & 90 & 0,154 & 106 & 109 & 0,189 \\
\hline Motorik & 91 & 103 & 0,01 & 97 & 107 & 0,004 \\
\hline Sosial emosi & 95 & 99 & 0,193 & 95 & 100 & 0,481 \\
\hline Adaptif & 98 & 99 & 0,082 & 95 & 99 & 0,05 \\
\hline
\end{tabular}

Tabel 3. Risiko keterlambatan perkembangan

\begin{tabular}{|c|c|c|c|c|c|c|}
\hline \multirow[b]{2}{*}{ Area } & \multicolumn{2}{|c|}{ Usia 3 bulan } & \multirow[b]{2}{*}{ Kemaknaan } & \multicolumn{2}{|c|}{ Usia 6 bulan $(\%)$} & \multirow[b]{2}{*}{ Kemaknaan } \\
\hline & $\begin{array}{l}\text { Risti } \\
(\%)\end{array}$ & $\begin{array}{c}\text { Risiko } \\
\text { rendah } \\
(\%)\end{array}$ & & $\begin{array}{l}\text { Risti } \\
(\%)\end{array}$ & $\begin{array}{c}\text { Risiko } \\
\text { rendah } \\
(\%)\end{array}$ & \\
\hline \multicolumn{7}{|l|}{ Kognitif } \\
\hline Normal & $38(60,3)$ & $44(80)$ & $\mathrm{p}=0,021$ & $45(71,4)$ & $50(90,9)$ & $\mathrm{p}=0,008$ \\
\hline Terlambat & $25(39,7)$ & $11(20)$ & $\mathrm{RR}=1,984(\mathrm{IK} 95 \% 1,078-3,652)$ & $18(28,6)$ & $5(9,1)$ & $\mathrm{RR}=3,143(\mathrm{IK} 95 \% 1,294-7,906)$ \\
\hline \multicolumn{7}{|c|}{ Komunikasi } \\
\hline Normal & $40(63,5)$ & $44(80)$ & $\mathrm{p}=0,048$ & $51(81)$ & $52(94,5)$ & $\mathrm{p}=0,027$ \\
\hline Terlambat & $23(36,5)$ & $11(20)$ & $\mathrm{RR}=1,825$ (IK 95\%0,981-3,396) & $12(19)$ & $3(5,5)$ & $\mathrm{RR}=3,492(\mathrm{IK} 95 \%$ 1,039-11,738) \\
\hline \multicolumn{7}{|c|}{ Motorik } \\
\hline Normal & $35(55,6)$ & $47(85,5)$ & $\mathrm{p}=0,000$ & $44(69,8)$ & $51(92,7)$ & $\mathrm{p}=0,002$ \\
\hline Terlambat & $28(44,4)$ & $8(14,5)$ & $\mathrm{RR}=3,056(\mathrm{IK} 95 \% 1,521-6,138)$ & $19(30,2)$ & $4(7,3)$ & $\mathrm{RR}=4,147(\mathrm{IK} 95 \% 1,502-11,451)$ \\
\hline \multicolumn{7}{|c|}{ Sosial emosi } \\
\hline Normal & $38(60,3)$ & $42(76,4)$ & $\mathrm{p}=0,063$ & $44(69,8)$ & $39(70,9)$ & $\mathrm{p}=0,899$ \\
\hline Terlambat & $25(39,7)$ & $13(23,6)$ & $\mathrm{RR}=1,679$ (IK 95\% 10,955-2,952) & $19(30,2)$ & $16(29,1)$ & $\mathrm{RR}=1,037$ (IK 95\% 0,593-1,811) \\
\hline \multicolumn{7}{|c|}{ Adaptif } \\
\hline Normal & $43(68,3)$ & $47(85,5)$ & $\mathrm{p}=0,028$ & $49(77,8)$ & $52(94,5)$ & $\mathrm{p}=0,010$ \\
\hline Terlambat & $20(31,7)$ & $8(14,5)$ & $\mathrm{RR}=2,183(\mathrm{IK} 95 \%$ 1,046 - 4,555) & $14(22,2)$ & $3(5,5)$ & $\mathrm{RR}=4,074(\mathrm{IK} 95 \%$ 1,235-13,473) \\
\hline
\end{tabular}


Rini Purwanti dkk: Penilaian perkembangan bayi risiko tinggi dan rendah pada usia 3 dan 6 bulan dengan instrumen Bayley III

Tabel 4. Jumlah faktor risiko perinatal dan keterlambatan perkembangan

\begin{tabular}{|c|c|c|c|c|c|c|}
\hline \multirow[b]{2}{*}{ Area } & \multicolumn{2}{|c|}{3 bulan } & \multirow[b]{2}{*}{$\mathrm{p}$} & \multicolumn{2}{|c|}{6 bulan } & \multirow[b]{2}{*}{$\mathrm{p}$} \\
\hline & $\begin{array}{l}\text { Normal } \\
\mathrm{n}(\%)\end{array}$ & $\begin{array}{c}\text { Terlambat } \\
\text { n (\%) }\end{array}$ & & $\begin{array}{c}\text { Normal } \\
\mathrm{n}(\%)\end{array}$ & $\begin{array}{c}\text { Terlambat } \\
\text { n (\%) }\end{array}$ & \\
\hline $\begin{array}{l}\text { Kognitif } \\
<3 \text { faktor risiko } \\
>3 \text { faktor risiko }\end{array}$ & $\begin{array}{c}33(64,7) \\
6(50)\end{array}$ & $\begin{array}{c}18(35,3) \\
6(50)\end{array}$ & 0,059 & $\begin{array}{c}38(74,5) \\
7(58,3)\end{array}$ & $\begin{array}{c}13(25,5) \\
5(41,7)\end{array}$ & 0,001 \\
\hline $\begin{array}{l}\text { Komunikatif } \\
<3 \text { faktor risiko } \\
>3 \text { faktor risiko }\end{array}$ & $\begin{array}{c}34(66,7) \\
7(58,3)\end{array}$ & $\begin{array}{c}17(33,3) \\
5(41,7)\end{array}$ & 0,017 & $\begin{array}{l}40(78,4) \\
11(91,7)\end{array}$ & $\begin{array}{c}11(21,6) \\
1(8,3)\end{array}$ & 0,000 \\
\hline $\begin{array}{l}\text { Motorik } \\
<3 \text { faktor risiko } \\
>3 \text { faktor risiko }\end{array}$ & $\begin{array}{c}31(60,8) \\
4(33,3)\end{array}$ & $\begin{array}{c}20(39,2) \\
8(66,7)\end{array}$ & 0,378 & $\begin{array}{c}38(74,5) \\
6(50)\end{array}$ & $\begin{array}{c}13(25,5) \\
6(50)\end{array}$ & 0,002 \\
\hline $\begin{array}{l}\text { Sosial emosi } \\
<3 \text { faktor risiko } \\
>3 \text { faktor risiko }\end{array}$ & $\begin{array}{c}31(60,8) \\
7(58,3)\end{array}$ & $\begin{array}{c}20(39,2) \\
5(41,7)\end{array}$ & 0,101 & $\begin{array}{l}34(66,7) \\
10(83,3)\end{array}$ & $\begin{array}{c}17(33,3) \\
2(16,7)\end{array}$ & 0,002 \\
\hline $\begin{array}{l}\text { Adaptif } \\
<3 \text { faktor risiko } \\
>3 \text { faktor risiko }\end{array}$ & $\begin{array}{c}36(70,6) \\
7(58,3)\end{array}$ & $\begin{array}{c}15(29,4) \\
5(41,7)\end{array}$ & 0,004 & $\begin{array}{c}38(74,5) \\
9(75)\end{array}$ & $\begin{array}{c}12(23,5) \\
3(25)\end{array}$ & 0,000 \\
\hline
\end{tabular}

Tabel 5. Klasifikasi penilaian Bayley ${ }^{13}$

\begin{tabular}{cl}
\hline Jumlah nilai komposit & Klasifikasi \\
\hline$\geq 130$ & Sangat superior \\
$120-129$ & Superior \\
$110-119$ & Di atas rata-rata \\
$90-109$ & Rata - rata \\
$80-89$ & Di bawah rata-rata \\
$70-79$ & Perbatasan \\
$\leq 69$ & Sangat rendah \\
\hline
\end{tabular}

klinis (Tabel 2). Area motorik halus $(\mathrm{p}=0,02)$ dan komunikasi ekspresif $(\mathrm{p}=0,001)$ lebih terpengaruh pada usia 6 bulan.

Risiko keterlambatan perkembangan meningkat untuk semua area pada kelompok bayi risti pada usia 3 bulan (Tabel 3) dan didapatkan perbedaan statistik yang bermakna. Risiko keterlambatan di area motorik merupakan yang tertinggi pada dua kali pemantauan.

Faktor risiko yang banyak dijumpai selama masa perinatal (Tabel 4) berhubungan dengan kejadian keterlambatan pada usia 3 ataupun 6 bulan di area kognitif, komunikasi dan adaptif $(\mathrm{p}<0,05)$. Pada area motorik dan sosial emosi, jumlah morbiditas perinatal berpengaruh di usia 6 bulan.

\section{Pembahasan}

Proporsi bayi laki-laki pada kelompok risti lebih banyak 1,3 kali dari perempuan, konsisten dengan beberapa penelitian. ${ }^{14,15}$ Diduga terkait dengan perbedaan steroid gonad in utero sehingga kemampuan fetus laki-laki menghadapi stres lebih rendah. Prematuritas merupakan masalah utama, walaupun prevalens secara global berkurang. ${ }^{16}$ Asfiksia dan sepsis menempati urutan berikutnya, serupa dengan penelitian Rahim $\mathrm{dkk}^{17}$ di Pakistan. Mokhtar-Yola dkk ${ }^{18}$ di Nigeria menemukan hal sebaliknya, yaitu sepsis sebagai morbiditas perinatal utama, diikuti dengan asfiksia dan prematuritas. Hal tersebut menunjukkan bahwa pada negara berkembang, infeksi masih menjadi masalah perinatal utama. Hubungan status sosial ekonomi rendah dengan kejadian morbiditas perinatal dijelaskan oleh Luo dkk ${ }^{19}$ terkait dengan kekurangan aksesibilitas pelayanan kesehatan.

Pertumbuhan bayi risti lebih rendah pada usia 3 dan 6 bulan daripada bayi risiko rendah terkait dengan fase tumbuh kejar pada subjek yang mayoritas merupakan bayi prematur belum tercapai. Kosinska $\mathrm{dkk}^{20}$ mengatakan bahwa $68 \%$ bayi prematur baru mencapai tumbuh kejar di usia 1 tahun. Prevalens gagal tumbuh yang meningkat di usia 6 bulan pada kelombok risti diduga adalah karena faktor kemiskinan dan pendidikan orangtua yang rendah. 
Rini Purwanti dkk: Penilaian perkembangan bayi risiko tinggi dan rendah pada usia 3 dan 6 bulan dengan instrumen Bayley III

Median nilai komposit pada area kognitif dan motorik di usia 3 dan 6 bulan pada kelompok risti lebih rendah daripada bayi risiko rndah secara statistik bermakna, namun secara klinis tidak bermakna. Hal tersebut disebabkan nilai median seluruh subtes berada pada klasifikasi rata-rata, yaitu pada nilai komposit 90-109 (Tabel 5). Sebaran faktor risiko morbiditas pada kelompok risti yang tidak normal dapat menyebabkan kondisi tersebut. Pola asuh dan stimulasi di rumah tidak diperhitungkan dan dapat menjadi faktor perancu. DePaiva $\mathrm{dkk}^{21}$ menyatakan bahwa nilai komposit Bayley III di area kognitif dan komunikasi lebih rendah pada bayi dari latar belakang sosial ekonomi rendah, terkait dengan pola asuh dan stimulasi anak. Cusson ${ }^{22}$ meneliti bahwa sampai usia 6 bulan, bayi prematur tidak mengalami hambatan komunikasi sehingga membutuhkan pengamatan lebih lanjut.

Risiko keterlambatan perkembangan semakin jelas terlihat pada seluruh area di usia 6 bulan, kecuali untuk bidang sosial emosi. Perkembangan motorik memiliki peningkatan risiko keterlambatan terkait dengan prevalens gagal tumbuh yang meningkat. Gangguan pertumbuhan dapat menyebabkan abnormalitas tonus otot sementara yang dapat menghilang pada rentang usia 6-12 bulan. ${ }^{23,24}$

Penurunan faktor risiko di area sosial emosi diduga terjadi akibat efek Hawthorne, karena penilaian di area ini dilakukan melalui kuisioner yang diisi oleh pengasuh. Pengasuh akan berusaha sebaik mungkin untuk mengingat tahapan perkembangan yang sudah dicapai. Kemungkinan lain adalah Bayley III belum dapat mendeteksi gangguan sosial emosi sampai usia 6 bulan. Morbiditas yang dialami selama masa perinatal mempengaruhi perkembangan seorang bayi. Elenjickal $\mathrm{dkk}^{25}$ membuat sistem nilai untuk melakukan kategori risiko keterlambatan perkembangan berdasarkan jumlah morbiditas perinatal. Hasil pengamatan lebih lanjut pada penelitian tersebut, dengan menggunakan Denver Development Screening Test (DDST) menunjukkan semakin banyak morbiditas perinatal, semakin tinggi risiko keterlambatan.

Studi kami merupakan studi pertama di Indonesia yang mengikuti perkembangan bayi pada usia 3 dan dilanjutkan pada usia 6 bulan, baik pada kelompok risti maupun risiko rendah dengan menggunakan instrumen Bayley III. Morbiditas perinatal merupakan faktor risiko yang dianggap sebagai penyebab gangguan tumbuh kembang. Faktor lain seperti gangguan pranatal tidak diperhitungkan sebagai suatu faktor risiko. Stimulasi yang dilakukan oleh pengasuh seharihari tidak dipergunakan sebagai variabel penelitian dan sangat mungkin menjadi suatu faktor perancu.

\section{Kesimpulan}

Perkembangan bayi risti mengalami keterlambatan di area kognitif dan motorik pada usia 3 dan 6 bulan dibanding bayi risiko rendah. Semakin bertambah usia bayi risti, semakin banyak gangguan perkembangan yang akan timbul. Risiko keterlambatan makin jelas terlihat di usia 6 bulan, kecuali untuk area sosial emosi. Jumlah morbiditas perinatal berhubungan terhadap derajat keterlambatan perkembangan. Hasil penelitian kami perlu ditindaklanjuti karena proses tumbuh kembang masih berlanjut dan risiko terjadi gangguan yang belum terdeteksi saat ini masih dapat terjadi di kemudian hari.

\section{Daftar pustaka}

1. Sularyo TS. Periode kritis pada masa tumbuh kembang balita. Dalam: Sularyo TS,penyunting. Deteksi dan intervensi dini penyimpangan tumbuh kembang dalam upaya optimalisasi kualitas sumber daya manusia. Pendidikan Kedokteran Berkelanjutan Ilmu Kesehatan Anak Jakarta. Jakarta:Balai Penerbit FKUI;1996.h.132.

2. Committee for Practice and Ambulatory Medicine. Recommendation for preventive pediatric health care. Pediatrics.2000;105:645-6.

3. Godbole K, Barve S, Chaudari S. Early predictors of neurodevelopmental outcome in high-risk infant. Indian J Pediatr.1997;14:491-5.

4. Allen MC. Outcome and follow-up risk infants. Dalam: Taeusch HW, Ballard RA, penyunting. Avery's diseases of the newborn. Edisi ke-7. Philadelphia:WB Saunders;1998.h.413-28.

5. Soedjatmiko. Stimulasi psikososial pada bayi risiko tinggi. Dalam: Hot Topics in Pediatrics II. Pendidikan Kedokteran Berkelanjutan Ilmu Kesehatan Anak XLV. Jakarta:Balai Penerbit FKUI;2002.h.28-46.

6. Stoll BJ, Kliegman RM. The High risk infant. Dalam: Behrman RE, Kliegman RM, Jenson HB, penyunting. Nelson textbook of pediatric. Edisi ke-18. Philadelphia: WB Saunders;2007.h.698-710. 
Rini Purwanti dkk: Penilaian perkembangan bayi risiko tinggi dan rendah pada usia 3 dan 6 bulan dengan instrumen Bayley III

7. Alam A, Sukadi A, Risan NA, Dhamayanti M. Preterm and low birth weight as risk factors for infant delayed development. Paediatr Indones 2008;48:1-4.

8. Chen IC, Chen CL, Wong MK, Chung CY, Chen CH, Sun $\mathrm{CH}$. Clinical analysis of 1048 children with developmental delay. Chang Gung Med J 2002;25:743-50.

9. Ermawati T,Syarif I, Daili S. Perkembangan bayi/anak sehat usia 4-18 bulan yang berkunjung untuk imunisasi di beberapa Puskesmas dan Poliklinik IKA RSUP Dr M Djamil Padang. Abstrak KONIKA Bali 2002.

10. Susanah S, Tanuwidjaya S, Rusmil K. Gambaran perkembangan anak balita di daerah kumuh perkotaan kelurahan Sukapura kecamatan Kiaracondong kotamadya Bandung. Abstrak KONIKA Bali 2002.

11. Committee and Children with Disabilities, American Academy of Pediatrics. Developmental surveillance and screening of infants and young children. Pediatrics 2001;108: 192-6.

12. Hutchon B. Introducing the Bayley-III. Diunduh dari: http://www. pyschcorp.com.Diakses tanggal 23 Oktober 2006.

13. Zimmerman IL, Violette GS, Pond RE. Diunduh dari: http// harcourtassessment.com /hail Images/ pdfl technical_ reports/PLS4_TechReport.pdf. Diakses tanggal 23 Oktober 2006.

14. Mage DT, Donner EM. The fifty percent male excess of infant respiratory mortality. Act Paediatr 2004;93:1210-5.

15. Elsmen E, Steen M, Hellstrom-Westas L. Sex and gender differences in newborn infants:why are boys at increased risk? JMHG 2004;1:303-11.

16. Hendrick B. Premature births decline in US [Internet]
2010 ; diunduh 3 Februari 2011. Diakses dari: http:// www.medscape.com/viewarticle/721675.

17. Rahim F, Jan A, Mohummad J, Iqbal H. Pattern and outcome of admissions to neonatal unit of Khyber Teaching Hospital, Peshawar. Pak J Med Sc 2007;23:24953.

18. Mukhtar-Yola M, Iliyasu Z. A review of neonatal morbidity and mortality in Aminu Kano Teaching Hospital, Northern Nigeria. Trop Doct 2007;37:130-2.

19. Luo ZC, Wilkins R, MS Kramer. Effect of neighbourhood income and maternal education on birth outcomes:a population-based study. CMAJ 2006;10:1415-20.

20. Kosinska M, Stoinska B, Gadzinowski J. Catch-up growth among the low birth weight infants: estimation of the time of occurrence of compensatory events. Antropol Rev 2004;67:87-95.

21. de Paiva GS, de Souza Lima ACVM, Lima MC, Eickmann SH. The effect of poverty on developmental screening scores among infants. Sao Paulo Med J 2010;128:276-83.

22. Cusson RM. Factors influencing language development in preterm infant. JOGNN 2003;32:402-9.

23. Chaudhari S, Bhalerao M, Chitale A, Patil B, Pandit A, Hoge M. Transient tone abnormalities in "high risk" infant and cognitive outcome at five years. Indian J Pediatr 2010;47:931-5.

24. Kitamoto I, Kukita J, Kurokawa T, Chen YJ, Minami T, Ueda K. Transient neurologic abnormalities and BAEPs in high-risk infants.Pediatr Neurol 1990;6:319-25.

25. Elenjickal MG, Thomas K, Sushamabai S, Ahamaed SK. Development of high-risk newborn-A follow-up study from birth to one year. Indian J Paediatr 2009;1:1-4. 